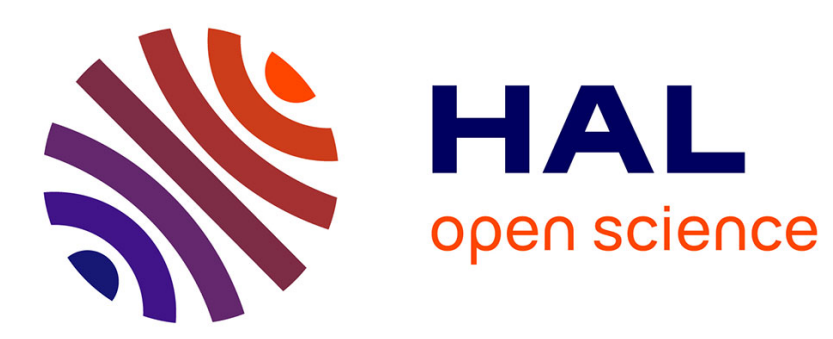

\title{
Genetic and epigenetic factors contributes to the onset of Preeclampsia
}

\author{
S.T. Chelbi, D. Vaiman
}

\section{To cite this version:}

S.T. Chelbi, D. Vaiman. Genetic and epigenetic factors contributes to the onset of Preeclampsia. Molecular and Cellular Endocrinology, 2008, 282 (1-2), pp.120. 10.1016/j.mce.2007.11.022 . hal00531967

\section{HAL Id: hal-00531967 https://hal.science/hal-00531967}

Submitted on 4 Nov 2010

HAL is a multi-disciplinary open access archive for the deposit and dissemination of scientific research documents, whether they are published or not. The documents may come from teaching and research institutions in France or abroad, or from public or private research centers.
L'archive ouverte pluridisciplinaire HAL, est destinée au dépôt et à la diffusion de documents scientifiques de niveau recherche, publiés ou non, émanant des établissements d'enseignement et de recherche français ou étrangers, des laboratoires publics ou privés. 


\section{Accepted Manuscript}

Title: Genetic and epigenetic factors contributes to the onset of Preeclampsia

Authors: S.T. Chelbi, D. Vaiman

PII: $\quad$ S0303-7207(07)00424-8

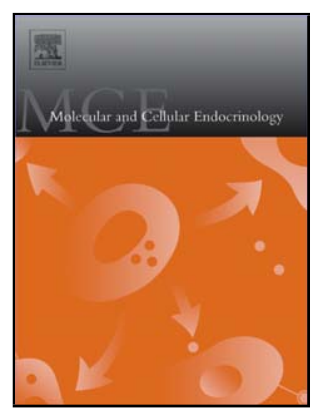

DOI: $\quad$ doi:10.1016/j.mce.2007.11.022

Reference: $\quad$ MCE 6751

To appear in: $\quad$ Molecular and Cellular Endocrinology

Please cite this article as: Chelbi, S.T., Vaiman, D., Genetic and epigenetic factors contributes to the onset of Preeclampsia, Molecular and Cellular Endocrinology (2007), doi:10.1016/j.mce.2007.11.022

This is a PDF file of an unedited manuscript that has been accepted for publication. As a service to our customers we are providing this early version of the manuscript. The manuscript will undergo copyediting, typesetting, and review of the resulting proof before it is published in its final form. Please note that during the production process errors may be discovered which could affect the content, and all legal disclaimers that apply to the journal pertain. 


\title{
Genetic and epigenetic factors contributes to the onset of Preeclampsia
}

\author{
CHELBI S.T. ${ }^{1,2}$, VAIMAN D. ${ }^{1,2,3}$ \\ ${ }^{1}$ Institut Cochin Equipe 21, Université Paris Descartes, CNRS UMR 8104 - IFR Alfred Jost, Faculté de Médecine, \\ 24 Rue du Faubourg Saint-Jacques, 75014 Paris, France \\ 2 INSERM U567, Paris, France \\ ${ }^{3}$ Animal Genetics Department, Institut National de la Recherche Agronomique, INRA- 78352 Jouy-en-Josas, \\ France \\ Corresponding author full address: \\ Daniel Vaiman \\ PhD DR2 INRA \\ Equipe 21 Génomique et Epigénétique des Pathologies Placentaires (GEPP) Institut Cochin \\ 24 rue du Faubourg St Jacques, 75014 Paris, France \\ vaiman@cochin.inserm.fr \\ Tel: +33144412301 \\ Fax: +33144412302
}

\section{List of abbreviations}

PE : Preeclampsia - IUGR : Intra uterine growth restriction - HELLP : Haemolysis, elevated liver enzymes and low platelets - s-FLT1: Soluble Fms-like tyrosine kinase 1 - STOX1: Storkhead-box protein 1 - ST : Syncytiotrophoblast - CT : Cytotrophoblast - EVCT: Extravillous cytotrophoblast - NO: Nitric oxide - MMP: Matrix metalloproteinase - u-PA: Urokinase-type plasminogen activator - t-PA: Tissue-type plasminogen activator - TIMP: Tissue inhibitor of metalloproteinase - PAI-1 and PAI-2: plasminogen activator inhibitor 1 and 2 - hCG: Human chorionic gonadotrophin - TGF $\beta$ : Transforming growth factor $\beta$ - IGFBP-1: Insulin-like growth factor binding protein 1 - EGF: Epithelial growth factor UNK: Uterine natural killer - HIF1: Hypoxia inducible factor 1 - SSH: Suppressive subtractive hybridization - hPL: Human placental lactogen - PSG: Pregnancy specific glycoprotein - ANGPTL4 : Angiopoietin-like 4 - PPAR $\gamma$ :Peroxisome-proliferator-activated receptor $\gamma$ - SERPIN: Inhibitor of serine protease - AGT: Angiotensinogen - VEGF :Vascular endothelial growth factor - PlGF: Placental growth factor - Eng: Endoglin - eNOS: Endothelial nitric oxide synthase - LPO: Lipid peroxide - TXA2: Tromboxan A2 - PGI2: Prostaglandin I2 (prostacyclin) - KIR : Killer Immunoglobulin-like Receptor - MAZF: MYCassociated zinc finger protein - RXR: Retinoid X receptor - MSAP-PCR: Methylation Sensitive Arbitrarly Primed Polymerase Chain Reaction - MeDIp: Methylated DNA Immunoprecipitation - 


\begin{abstract}
Preeclampsia (PE) is a major cause of perinatal materno-fetal morbidity and pregnancy linked-mortality in industrialized countries. Clinically, PE associates maternal pregnancyinduced hypertension with proteinuria. PE is often considered as a two-stage disease. The first stage is a shallow cytotrophoblastic invasion which induces cycles of hypoxia-reoxygenation at the placental level. Subsequently an abnormal expression pattern occurs and is followed by the release of soluble factors and trophoblastic debris in the maternal blood flow. These stimuli trigger the second phase of the disease, the maternal syndrome. Although some molecular actors have been recently identified, mechanisms of the disease onset remains poorly understood. It seems that combinations of genetic, epigenetic and environmental factors are involved. Here, we suggest that epigenetic marks have to be considered to decipher the physiopathological process of PE. Since these marks must be established early and are traceable in the maternal blood flow, they could constitute a diagnosis tool.
\end{abstract}

Keywords: preeclampsia, placental disease, genetics, epigenetics 


\section{Introduction}

At the blastocyst stage, the human embryo is anchored into the uterine wall during the implantation process. From then on, a part of the extra-embryonic tissues invades the endometrium, which leads to the formation of a placenta. The placenta is a transient organ essential for maintaining pregnancy and ensuring embryonic and foetal growth. Indeed, this organ is crucial for adequately establishing an immunological tolerance to the embryo, similar to a hemi-allogenic graft, for the secretion of hormones, and for nutrients and gas exchanges. Placentation is a multi-step process where the maternal endometrium must first undergo a decidualization, characterised by structural and biochemical modifications. Then, interactions between the trophoblasts, which are the principal cell type of the placenta, and decidual components lead to implantation sensu stricto. Finally, trophoblastic cells invade the decidua and restructure the uterine vascular system to increase the vascular flow at the utero-placental interface. This ultimate human-specific step leads to the formation of a hemochorial placenta at the end of the first trimester. Alterations of any event in this sequence may lead to obstetrical complications for the mother and/or the foetus. The main placental diseases are preeclampsia (PE) and Intra-Uterine Growth Restriction (IUGR).

Clinically, PE associates maternal pregnancy-induced hypertension $(>140 / 90 \mathrm{mmHg})$ with proteinuria ( $>0.3 \mathrm{~g}$ a day), and in the majority of cases, mild to severe oedema. This syndrome affects up to $10 \%$ of the pregnancies (Sibai et al., 1997, Witlin and Sibai, 1998, Cecil et al., 2004). It is the major cause of perinatal materno-fetal morbidity and stays the main cause of pregnancy linked-mortality in industrialized countries (2000). Indeed, this multisystemic disease can lead to severe clinical conditions, such as HELLP (ㅂaemolysis, Elevated Liver enzymes and Low Platelets) when a haemolytic process is observed and more rarely to eclampsia, when generalised seizures appear. Both threaten the life of the mother. The only 
way to resolve the symptoms is the delivery of the placenta. Thus, extraction of the foetus before normal term is the classical treatment for PE, leading to iatrogenic prematurity. Furthermore, in over $25 \%$ of the cases, PE induces IUGR, a condition defined by a rupture of the foetal growth curve, leading generally to low weight newborns, according to a given cutoff (Battaglia, 1967, Breart et al., 1982, Seeds and Peng, 1998, Ergaz et al., 2005). Consequently, PE indirectly contributes to the risk of developing the metabolic Syndrome (a condition associated with low weight at birth characterized by obesity, type II diabetes, and cardiovascular disease at adult age (Barker et al., 1989)). PE is a real medical challenge since women suffering PE typically develop clinical signs and symptoms from mid-gestation (after 20 weeks of pregnancy), when it is too late to efficiently treat and limit the disease. Although the disease appears late, it is now widely recognized that the physiopathological process starts as early as the end of the first trimester of pregnancy. In PE, a shallow trophoblastic invasion of the spiral uterine arteries leads to the maintenance of their contractile properties and to the increase of the vascular resistance (Gerretsen et al., 1981, Kaufmann et al., 2003, Fisher, 2004). This defective invasion triggers a cascade of events that eventually leads to the appearance of the clinical signs (Roberts and Lain, 2002, Redman and Sargent, 2005, Roberts and Gammill, 2005). Research about PE has been extensive during the last decade, but significant improvements in early prediction or diagnosis of the disorder are still awaited. Nevertheless several physiopathological pathways have been elucidated in PE, with the identification of master factors, such as sFlt-1 (soluble Fms-like tyrosine kinase 1, Maynard et al., 2003) and endoglin (Venkatesha et al., 2006), two proteins influencing angiogenesis and vasculogenesis, and STOX1 (Storkhead-box protein 1) a transcriptional factor that seems to genetically predispose to PE in Dutch families (van Dijk et al., 2005). However, PE aetiology remains poorly understood since the disease is heterogeneous, multi-factorial and widely differs in women according to specific risk factors (Duckitt and Harrington, 2005) 
(primiparity, age of the mother, smoking habits, previous hypertension, familial history of gravidic hypertension, etc.). This review provides an overview of the current theories and emerging perspectives in the field of elucidating the physiopathological process of PE, focusing in particular on putative epigenetic signatures characterizing the pathological placentas.

\section{Placentation process}

During implantation the undifferentiated mononuclear trophoblast cells reside in two different types of highly specialized chorionic villi, the floating villi that float in maternal blood and anchoring villi present within the uterine wall that attach the fetus to the mother (cf. Figure 1). These highly proliferative, undifferentiated trophoblast cells follow two separate pathways of differentiation (Cross et al., 1994). In floating villi, they have the unique ability to fuse and form the multinucleated syncytiotrophoblast (ST) layer, which functions as a natural physical barrier between maternal and foetal cells. Since ST is directly in contact with maternal blood, it mediates gas and nutrient exchanges for the developing foetus. In anchoring villi, proliferative cytotrophoblast (CT) cells differentiate in tumor-like cells, extravillous cytotrophoblasts (EVCT) which will invade the maternal endometrium.

The first phase of invasion results in the creation of a trophoblastic shell inside the maternal vessels which form intravascular plugs. These plugs act like filters that protect the foetus from teratogenic molecules like free oxygen radicals during organogenesis (Jauniaux et al., 2003). Progressively due to low $\mathrm{O}_{2}$ pressure, these plugs disaggregate and oxygen pressure starts to increase steadily from 9-10 weeks. This signal triggers EVCT growth and differentiation. From then on (between 11-13 weeks), a second invasion wave starts, which constitutes a specificity of human pregnancies (Robillard et al., 2002) leading to the creation of the hemochorial placenta. Two differentiated populations of EVCT have been identified, interstitial cytotrophoblasts and endovascular cytotrophoblasts. Interstitial cytotrophoblasts 
invade deeply the decidual stroma and fuse to form multinuclear giant cells at the end of their invasion path (Lyall, 2005). These interstitial trophoblasts release vasodilators (e.g. nitric oxide (NO) and carbon monoxide (CO)) that act on the spiral arteries before destruction by endovascular trophoblasts (Lyall, 2005). Endovascular cytotrophoblasts invade the lumen of the uterine spiral arteries, cross the first third of the adjacent myometrium, anchor to the vessel wall, and promote arterial dilatation. Then, these endovascular cytotrophoblasts remodel extensively the arteries, which eventually lose their smooth muscle layer, and therefore vasomotor control. Finally, they express markers of endothelial cells, including angiogenic factors and their receptors, and replace the endothelial lining of the arteries with a pseudo-endothelium. Consequently the resistance of the uterine arteries decreases and the intervillous blood flow increases sufficiently to permit foetal growth during the second part of pregnancy (Zhou et al., 1997, Damsky and Fisher, 1998).

The temporal and spatial regulation of cytrophoblast invasion is believed to be mediated by trophoblastic factors in an autocrine way and by uterine factors in a paracrine way (Bischof et al., 2000, Staun-Ram and Shalev, 2005). The EVCT must invade the decidua during the first trimester (from 6 to 18 weeks) in a tightly controlled manner, guided by the accurate recognition of membrane and extracellular matrix components (mainly integrins and cadherins) and by the controlled solubilisation of this matrix by the secretion of matrix metalloproteases (such as MMP-2 and MMP-9) (Bischof et al., 2002, Cohen et al., 2006), serine proteases ( Plasminogen Activator t-PA), and their inhibitors (respectively the tissue metalloprotease inhibitors TIMPs, and the PA inhibitors PAI-1 and PAI-2) (Matrisian, 1990, Kolben et al., 1996, Hu et al., 1999). ST cells also secrete hormones such as human Chorionic Gonadotrophin (hCG) and progesterone that modulate uterine development and uterine factors secretion (Islami et al., 2001, Staun-Ram and Shalev, 2005). In parallel, the maternal 
endometrium switches the composition of its extracellular matrix components. In particular, it modifies its composition by the synthesis of collagen IV, laminine, heparan sulphate, proteoglycans and its cell adhesion molecules by the synthesis of specific integrins and uterine cell-surface glycoproteins such as Mucin 1 (Carson et al., 1998). Also, the endometrium secretes growth factors (TGF $\beta$, IGFBP-1, EGF etc), and TIMPs. All these modifications establish a fine molecular dialogue between the maternal and the foetal sides that equilibrate the invasion process (Staun-Ram and Shalev, 2005). Moreover, the decidua is colonized by macrophages, lymphocytes and uterine-specific cells of the immune system (uterine natural killer, uNK, cells). These cells secrete cytokines that will either stimulates or inhibits invasion by EVCT (Sargent et al., 2006).

\section{The onset of preeclampsia}

PE is commonly considered as a two-stages disease (Roberts and Gammill, 2005). The first stage relates to a partial failure of early trophoblast invasion and remodelling of the spiral arteries. Consequently, the vascular flow is restricted in PE placentas, and the insufficient blood supply to the placenta causes hypoxia. Ultimately, ischemic lesions induced by the oxidative stress appear (Granger et al., 2002, Gupta et al., 2005). The second stage is the maternal syndrome, which is characterized by an exaggerated systemic inflammatory response (Redman and Sargent, 2000) involving leukocyte and endothelial dysfunctions, thrombosis and a renin-angiotensin-aldosterone system activation (Elsheikh et al., 2001, Redman and Sargent, 2004). The stimuli that leads to clinical signs are believed to come from the stressed placenta (see figure 2).

\subsection{Primary placental causes of $P E$}

An emergent theory about PE is that abnormal placental perfusion (resulting from abnormal arterial remodelling) induces a blood intermittent flow leading to successive hypoxiareoxygenation and subsequent injuries (Hung and Burton, 2006). Placental oxidative stress 
can be the consequence of fluctuations in oxygen concentrations after hypoxia-reoxygenation through the actions of reactive oxygen species. The abnormal maintenance of chronic hypoxia in PE seems critical since it disables adaptative placental response and induces inappropriate gene expression profiles that might exacerbate placental defects (Zhou et al., 1998). Hypoxic effects are mainly mediated via the post-translational stabilisation of the hypoxia-inducible transcription factor HIF $1 \alpha$. In hypoxic conditions, the half-life of this protein is considerably augmented (Park et al., 2003). To achieve its regulatory activity, HIF1 $\alpha$ forms a heterodimer with HIF1 $\beta$ (ARNT). The physiological role of HIF-1 complex for correct placentation is clearly demonstrated. Indeed, in mutant mice where placentas have been deleted for Arnt, labyrinthine and spongiotrophoblast layers (two layers in intimate contact that structure the maternal and fetal vasculature and secure the maternal-fetal exchange in the mouse placenta) are reduced, demonstrating the structural function of hypoxia and HIF in placental differentiation (Adelman et al., 2000). Hypoxia has significant effects on placental development, causing hypercapillarization (angiogenesis) of the villous vasculature (Kingdom and Kaufmann, 1997). Hypoxia also stimulates trophoblasts proliferation whereas strong villi oxygenation reduces trophoblast proliferation (Kingdom and Kaufmann, 1997). Therefore, oxygen is an essential developmental regulator of the villous vascular tree. The anomalies observed in PE placentas are in accordance with an abnormal maintenance of hypoxia. Consistently, using a transcriptomic approach based on Suppressive Subtractive Hybridization (SSH) between cDNAs obtained from first-trimester human placenta villi exposed either to normoxic or hypoxic condition during 3 hours, we have shown that genes involved in angiogenesis and in proliferation are significantly overrepresented in hypoxic conditions (Mondon et al., 2005). Thus, the maintenance of the HIF-1 complex leads to the inappropriate expression of its placental target genes thereby disturbing angiogenesis, trophoblast proliferation and differentiation (Adelman et al., 2000, Cowden Dahl et al., 2005). 
Accordingly, it seems that invasive EVCT dedifferentiate in giant cells that then lose their invasive power in PE placentas. Furthermore, when we compared the expression profile of placental villi from controls or pathological -PE, PE+IUGR, IUGR- placentas to the hypoxic subtracted libraries, to explore relationships between hypoxia in the first trimester placenta and placental pathologies, we identified 276 different genes altered both by hypoxia and placental diseases. Nine of these genes were mitochondrial, while 267 were nuclear (Vaiman et al., 2005). The increased placental mitochondrial activity could partially explain the hypoxic induced-oxidative stress (Wang and Walsh, 1998, Shibata et al., 2003). In our study, specific expression profiles characteristic of PE could be identified, as well as profiles specific of IUGR. Some of the genes found associated with PE had already been evaluated as putative markers of the placental pathological status, such as hCG and human placental lactogen (hPL), as well as pregnancy specific glycoproteins (PSGs). Also, we found that ANGPTL4 (Angiopoietin-like 4) is elevated in PE. It is a downstream target of PPAR $\gamma$ (peroxisome-proliferator-activated receptor $\gamma$ ), and is therefore supposed to regulate lipid metabolism and glucose homeostasis (Yoon et al., 2000). In mice, ANGPTL4 is increased in the plasma by fasting and decreased by high fat diet (Kersten and Wahli, 2000), demonstrating its involvement in lipid capture in difficult physiological conditions.

Among the hypoxia and PE-induced genes, we found members of the Inhibitors of Serine proteases (SERPIN) family, on which we further concentrated. Previous studies had demonstrated the existence of plasma level modifications of SERPINA8 (angiotensinogen, AGT), E1 (PAI-1) and B2 (PAI-2) in PE women (Estelles et al., 1994, Morgan et al., 1997, Estelles et al., 1998, Ohkuchi et al., 2001, Page et al., 2002). At the molecular level, SERPIN genes encode at least 36 proteins with a complex conserved structure but various functions (Silverman et al., 2001). They mainly act as protease inhibitors and are characterized by their "suicide" behaviour, involving an unusual covalent binding with the target protease(s), before 
the degradation of the SERPIN-protease complex (Patston and Gettins, 1996). They can also serve as storage proteins (ovalbumin), carrier proteins (steroid-binding globulin) and hormone precursors (angiotensinogen) without inhibitory function. Nevertheless, they are all homeostasis guardians which regulate several molecular pathways, such as inflammation, coagulation, fibrinolysis, complement activation and phagocytosis. These cascades are affected in placental diseases (Ness and Sibai, 2006). By the transcriptomic analysis, we confirmed that SERPING1 (C1 inhibitor), SERPINE1 (PAI-1) and SERPINE2 were induced by hypoxia and modified in terms of expression in placentas from PE pregnancies. Then we analyzed eighteen placental SERPIN by quantitative RT-PCR on cDNAs synthesized from control placentas or placentas which underwent pregnancies accompanied with PE, IUGR, or both. SERPINA3, $A 5, A 8, B 2, B 5, B 7$ presented significant differences in expression in at least one pathological situation. Some of the modifications observed may constitute a part of a compensatory mechanism limiting placental damages (Chelbi et al., 2007). We found in all the pathological placentas an increase of SERPINA3 ( $\alpha 1$-antichymotrypsin) expression, consistent with the idea that this protein inhibits chymotrypsin and thus might counterbalance inflammation (Kalsheker et al., 2002). On the other hand, the SERPINA5 (protein C inhibitor or PCI) is secreted to inactivate several proteases of the fibrinolytic system. Therefore, the transcription reduction that we observed for SERPINA5 may serve to control thrombosis. Similarly, SERPINB2 (PAI-2) that participates in fibrinolysis control (Booth, 1999) was found reduced in placental diseases. SERPINA8 $(A G T)$ has been involved in hypertensive diseases. We found it increased in some individuals but this modification was not systematic, possibly due to genetic heterogeneity. The T235M substitution (Jeunemaitre et al., 1997), which occurs at higher frequency in Caucasian and Japanese PE women (Kobashi et al., 1999, Nakajima et al., 2002) is in absolute linkage disequilibrium with the proximal promoter polymorphisms G(-6)A, which leads to higher basal levels of AGT (Morgan et al., 1997). This raises the idea 
that some of these expressional modifications may not only be compensatory mechanism but also may be due to a genetic predisposition for developing the disease and the maternal syndrome.

\subsection{Onset of the maternal syndrome}

The systemic endothelial cell dysfunction appears as the key event of the diverse clinical manifestations of PE (Roberts, 1999, Granger et al., 2002, de Jager et al., 2003). Indeed, increased maternal vascular permeability and enhanced vasoconstriction are major pathophysiological events in PE and clinically, proteinuria, and interstitial oedema are manifestations of the diminished endothelial barrier function that occur in the maternal circulation during PE (Roberts, 1999, Granger et al., 2002). However, the ill-defined links between the primary placental causes and the secondary systemic illness of PE are often debated to determine which stimuli initiate the maternal syndrome. In this regard, it has been proposed that insufficient uteroplacental circulation leads to placental hypoxia, oxidative stress, and consequently the release in the maternal blood flow of placental factors that disrupt normal endothelial barrier function and induce increased endothelial permeability (Roberts, 1999, Granger et al., 2002, de Jager et al., 2003, Myers et al., 2005). Recent Studies suggest that an excess in soluble Fms-like tyrosine kinase-1 (sFlt-1) and endoglin (Eng) production observed in serum of women with PE is a consequence of the placental hypoxia that occurs during abnormal placentation (Maynard et al., 2005, Venkatesha et al., 2006). The high blood pressure and proteinuria could in part be due to an excess in circulating sFlt-1 concentrations. Indeed, experiments carried out on rats have shown that administration of sFlt 1 to pregnant rats induces hypertension, proteinuria, and glomerular endotheliosis, the classic lesions of PE (Maynard et al., 2003). sFlt-1 is an endogenous antiangiogenic protein that is mainly produced by the placenta and acts by neutralizing the proangiogenic proteins VEGF (Vascular Endothelial Growth Factor) and PlGF (Placental Growth Factor). In accordance, PE women 
present low serum free PlGF and VEGF. VEGF is important not only in blood pressure regulation but also in maintaining the integrity of the glomerular filtration barrier. VEGF is a well-known angiogenic factor but it also induces the secretion of NO and vasodilator prostacyclins in endothelial cells, suggesting a role in decreasing vascular tone and blood pressure (Morbidelli et al., 1996, He et al., 1999). VEGF has been implicated in glomerular healing, and anti-VEGF compounds have been found to increase apoptosis, impair glomerular capillary repair, and increase proteinuria in a rat model of mesangioproliferative nephritis (Ostendorf et al., 1999). Therefore, it has been hypothesized that excess circulating sFlt1 secreted by the placenta in PE leads to systemic endothelial dysfunction, hypertension, and proteinuria by antagonizing circulating VEGF and PlGF. Eng is a co-receptor for transforming growth factor beta (TGF $\beta$ ) family proteins, expressed on the endothelial cells lining the blood vessels, and thereby plays an important role in maintaining the health and integrity of the vascular system. Further investigations revealed that the extracellular region of the Eng protein is released into maternal circulation. This soluble Eng circulates in very high quantities among women with severe forms of PE. The administration of soluble Eng to pregnant rats showed that this protein was indeed amplifying the vascular damage mediated by sFlt1, resulting in the symptoms of severe PE. sFlt1 binds to VEGF and PlGF, and soluble Eng binds TGF $\beta$, diverting the compounds from the mother's blood vessels. The sequestration of TGF- $\beta 1$ by soluble Eng impairs binding to its receptors and consequently, its downstream signalling, thereby weakening the activation of endothelial nitric oxide synthase (eNOS) and vasodilatation (Venkatesha et al., 2006). In response, the mother's blood pressure rises, forcing more blood to the placenta. Even though sFlt1 and Eng are major components of the disease, other placental molecules are certainly involved. For instance, the HIF complex increases the production of the potent vasoconstrictor Endothelin 1 and reduces that of NO vasodilatator, which contributes to the elevation of blood pressure and activation of the 
coagulation pathway. Hypoxia also increases the oxidative stress that has been implicated in the pathophysiology of PE, since it damages the maternal vascular endothelium. Indeed, free radicals released from the poorly perfused foeto-placental unit initiate lipid peroxidation by attacking polyunsaturated fatty acids in cell membranes and converting them to lipid peroxides (LPOs) and a variety of secondary metabolites (Hubel et al., 1989, Chappell et al., 1999). Uncontrolled peroxidation alters membrane fluidity and permeability; therefore, the LPOs and their secondary metabolites are then transported through the circulation by lipoproteins, causing damage at distant tissues. Lipid peroxidations together with the ratio of Tromboxan A2 (TXA2) to prostacyclin PGI2 accentuate vasoconstriction and platelet aggregation. Placental oxidative stress also leads to increased shedding of apoptotic and/or necrotic syncytiotrophoblast debris into the maternal circulation. There is evidence that such trophoblast debris interact with maternal leukocytes and endothelial cells to stimulate the release of proinflammatory cytokines, which could then trigger the maternal disease (Redman and Sargent, 2000). Indeed cytokines are thought to lead to widespread dysfunction of the vascular endothelium contributing to the overproduction of endothelin and thromboxan, enhanced vascular sensitivity to Angiotensin II, and reduced production of NO and prostacyclin. In addition, analysis on maternal serum from PE women showed that various protein concentrations are altered. A significant serum increase in hCG was found to be more prevalent in PE women (Barros et al., 2002). hPL and PSGs were found reduced at 17 weeks in the serum of patients who develop later a preeclamptic condition. SERPINB2 is decreased in both PE and IUGR in the maternal serum (Grancha et al., 1996, Schjetlein et al.,1999). This decrease correlates with a diminished level of SERPINB2 mRNA in IUGR placentas (Grancha et al., 1996, Chelbi et al., 2007). The placental secretion of these proteins might participate in the serum levels observed. Overall, these released molecules and others may act together in the maternal syndrome onset. 


\section{Causes of placental defects}

\subsection{Genetic causes of preeclampsia}

The molecular processes that cause poor placentation are more controversial and uncertain. It seems acceptable to think that any molecular anomalies that reduce the invasive capacity of EVCT could trigger PE and that factors involved in maternal response to placental defects are fundamental. Thus, the possibility of a genetic predisposition to PE has been considered. Indeed, frequency and severity of the disease are substantially higher in women with preexisting maternal hypertension, diabetes, previous PE, pre-existing thrombophilia and familial history of PE (sister/mother who suffered PE) (Duckitt and Harrington, 2005). Various candidate gene studies adopted the approach of trying to identify genetic associations by case/control studies, comparing the frequency of genetic variants in the two groups. Some genetic polymorphism appeared as influencing the maternal response to PE and adjusting the magnitude of the symptoms. Genes implicated in trombophilia, haemodynamics, cytokines, oxidative stress, lipid metabolism, angiogenesis and invasion were identified (Chappell and Morgan, 2006). For instance, as evoked before, SERPINA8 (AGT) has been involved in hypertensive diseases and the T235M / G(-6)A substitutions appear as a risk factor for PE since they are linked with higher basal levels of AGT. On the other hand, the MMP-9-1562T allele is associated with a reduced risk of $\mathrm{PE}$ and thus may protect against maladaptation of the spiral arteries and decreased decidual degradation. The elevated MMP-9 concentrations reported to be associated with the $-1562 \mathrm{~T}$ allele might be essential for the development of an adequate maternal-foetal interface early in pregnancy (Coolman et al., 2006). Genetic determinants of PE have also been searched by familial linkage analyses. Genome wide studies have shown significant linkage with several loci for PE: 2p12, 2p25, 9p13 (Harrison et al., 1997, Arngrimsson et al., 1999, Lachmeijer et al., 2001). Recently, STOX1 missense 
mutations have been suggested as predisposing to PE in Dutch families (van Dijk et al., 2005). This winged-helix transcriptional factor is a candidate for controlling polyploidization of EVCT that accompanies their differentiation. Several recent studies, however, contest the generality of the involvement of this gene (Iglesias-Platas et al., 2007). Further investigation on the function of STOX1 is therefore requested to evaluate the position of this gene in pathophysiological cascades leading to the onset of PE.

Maternal and paternal genetic factors contribute to the onset of PE (Cnattingius et al., 2004, Esplin et al., 2001). While PE is often considered as a disease of the first pregnancy, the risk increases when the women had limited sperm exposure with their partner, suggesting a maternal habituation to immunological sperm parameters (Verwoerd et al., 2002, Einarsson et al., 2003). Recent studies indicate that the materno-foetal immunological dialogue remains a highly significant component of a successful pregnancy (Hiby et al., 2004). Invasive cytotrophoblasts that infiltrate maternal endometrium during placentation express a unique combination of HLA-C, -E, and -G (Parham, 1996, Moffett-King, 2002). Among them only HLA-C is polymorphic. The uNK cells assigned to production of cytokines, express KIRs (Killer Immunoglobulin-like Receptors) that can recognize HLA-C. The combination of maternal KIR AA genotype with a foetal HLA-C2 is substantially associated with an increased risk of PE (Hiby et al., 2004). To summarize, placentation is probably better if trophoblast strongly stimulates uterine NK cells, which then produce cytokines necessary for an efficient invasion.

\subsection{Epigenetic alterations in preeclampsia}

Epigenetic features are implicated in the pathogenesis of PE. It has been described that Medically Assisted Procreation increases the risk of PE (Wang et al., 2002), suggesting that early gamete alterations (of epigenetic origin) may be sufficient to induce placental defects (Wang et al., 2002). STOX1 is located in the imprinted locus 10q21.1, and haplotype analysis 
showed a parent of origin effect. Indeed the maximum allele sharing in the affected siblings was seen for maternally derived alleles in all families. Also, invalidation of the imprinted $p 57-$ Kip2 gene in a mouse model leads to hypertension and proteinuria during pregnancy (Kanayama et al., 2002). This model cannot nevertheless account for the complete panoply of symptoms observed in human patients. Also, a recent transcriptomic analysis of these mice indicates that the onset of PE-like symptoms in these mice is environment-dependent (Knox and Baker, 2007).

For non-imprinted genes, epigenetic alterations are also possible in PE. Recently, methylation alterations of the SERPINB5 and SERPINA3 promoters have been demonstrated. Chim and co-workers achieved to PCR-amplify foeto-placental DNA released in the maternal blood circulation after bisulphite treatment (a treatment able to freeze DNA methylation by changing unmethylated cytosines to uraciles), and observed that the promoter region of SERPINB5 is undermethylated in PE cases compared to controls. In our laboratory, we have studied the SERPINA3 proximal promoter by post-bisulphite pyrosequencing and have shown that it is significantly hypomethylated at specific $\mathrm{CpG}$ positions in placentas from $\mathrm{PE}$ pregnancies compared with placentas from normal gestations. In this promoter, it appeared that demethylated $\mathrm{CpG}$ are prominently positioned into the putative binding sites of specific developmental regulators, such as homeodomain-containing proteins, and inflammatory modulators such as MAZF and RXR. RXR $\alpha /$ PPAR $\gamma$ heterodimers have been shown to present very important roles in trophoblast invasion and placental nutrient transport (Tarrade et al., 2001, Fournier et al., 2002). We also found putative binding site for HIF1 $\alpha$. This high concentration of binding sites involved in placental development suggests an early involvement of SERPINA3 in the onset of placental diseases. Moreover SERPINA3 has been described as a putative inhibitor of elastase. Elastase cleaves elastin and degrades collagen, fibronectin, laminin, and proteoglycans, leading to a reduction in matrix deposition 
(Thompson and Ohlsson, 1986, Vogelmeier et al., 1991). Consequently, we hypothesize that a pre-existing or early established demethylation of the SERPINA3 promoter induces an increase of expression due to an open chromatin state. The increased expression of SERPINA3 reduce the action of elastase, thus disturb matrix solubilisation. In this case, epigenetic alteration might participate in an inadequate, reduced trophoblastic invasion (Chelbi et al., 2007).

Methylation is a fundamental epigenetic mark that together with alterations of chromatin structure enables regulation of gene expression. The overall DNA methylation level changes in a tissue- and differentiation-dependent manner. Abnormal methylation patterns could therefore disturb cell differentiation and induce abnormal expression patterns. Such anomalies are the rule in cancer pathogenesis. We suggest that an abnormal methylation pattern may be a common mechanism of the pathogenesis of PE. Indeed, PE is a long term diseases (the duration of pregnancy), dependent on processes involving cell proliferation, differentiation and invasiveness. A promoter demethylation could contribute to render the chromatin accessible to transcription factors. For instance, several studies reported that the absence of CpG methylation at HIF1 $\alpha$ binding sites is required to allow gene transcriptional induction. Thus, demethylation may facilitate interaction of this transcription factor with the promoter in the hypoxic environment generated in PE. Consequently searching for genome-wide epigenetic alterations constitutes an interesting way to finding new actors early involved in the pathogenesis of placental diseases. We intend to carry on such global studies using Methylation Sensitive Arbitrarly Primed Polymerase Chain Reaction (MSAP-PCR) (Liang et al., 1998) and Methylated DNA Immunoprecipitation (MeDIp) (Weber et al., 2005) comparing DNA from normal and PE placentas. This work would be powerful to find new early actor and fully decipher pathogenesis. Moreover, this could lead to reveal new markers of PE. Indeed, the presence of syncitial debris, and thus of foeto-placental DNA in maternal 
blood could be used to follow such epigenetic alterations and predict early the development of a PE state in individual patients.

Acknowledgements: STC is a PhD student receiving a fellowship from the French Ministry of Research. English corrections by Ilies Kamoun are greatly acknowledged. 


\section{References}

2000 Report of the National High Blood Pressure Education Program Working Group on High Blood Pressure in Pregnancy. Am J Obstet Gynecol 183, S1-S22.

Adelman, D.M., Gertsenstein, M., Nagy, A., Simon, M.C. and Maltepe, E. 2000 Placental cell fates are regulated in vivo by HIF-mediated hypoxia responses. Genes Dev 14, 3191203.

Arngrimsson, R., Sigurard ttir, S., Frigge, M.L., Bjarnad ttir, R.I., Jonsson, T., Stefansson, H., Baldursdottir, A., Einarsdottir, A.S., Palsson, B., Snorradottir, S., Lachmeijer, A.M., Nicolae, D., Kong, A., Bragason, B.T., Gulcher, J.R., Geirsson, R.T. and Stefansson, K. 1999 A genome-wide scan reveals a maternal susceptibility locus for pre-eclampsia on chromosome 2p13. Hum Mol Genet 8, 1799-805.

Barker, D.J., Osmond, C. and Law, C.M. 1989 The intrauterine and early postnatal origins of cardiovascular disease and chronic bronchitis. J Epidemiol Community Health 43, 237-40.

Barros, J.S., Baptista, M.G. and Bairos, V.A. 2002 Human chorionic gonadotropin in human placentas from normal and preeclamptic pregnancies. Arch Gynecol Obstet 266, 6771.

Battaglia, F.C. 1967 Recent advances in medicine for newborn infants. J Pediatr 71, 748-58.

Bischof, P., Meisser, A. and Campana, A. 2000 Paracrine and autocrine regulators of trophoblast invasion--a review. Placenta 21 Suppl A, S55-60.

Bischof, P., Meisser, A. and Campana, A. 2002 Control of MMP-9 expression at the maternal-fetal interface. J Reprod Immunol 55, 3-10.

Booth, N.A. 1999 Fibrinolysis and thrombosis. Baillieres Best Pract Res Clin Haematol 12, 423-33.

Breart, G., Rabarison, Y., Plouin, P.F., Sureau, C. and Rumeau-Rouquette, C. 1982 Risk of fetal growth retardation as a result of maternal hypertension. Preparation to a trial on antihypertensive drugs. Dev Pharmacol Ther 4 Suppl, 116-23.

Carson, D.D., DeSouza, M.M. and Regisford, E.G. 1998 Mucin and proteoglycan functions in embryo implantation. Bioessays 20, 577-83.

Cecil, R.L., Goldman, L. and Ausiello, D.A. 2004 Cecil Textbook Of Medicine, Philadelphia.

Chappell, L.C., Seed, P.T., Briley, A.L., Kelly, F.J., Lee, R., Hunt, B.J., Parmar, K., Bewley, S.J., Shennan, A.H., Steer, P.J. and Poston, L. 1999 Effect of antioxidants on the occurrence of pre-eclampsia in women at increased risk: a randomised trial. Lancet 354, 810-6.

Chappell, S. and Morgan, L. 2006 Searching for genetic clues to the causes of pre-eclampsia. Clin Sci (Lond) 110, 443-58.

Chelbi, S.T., Mondon, F., Jammes, H., Buffat, C., Mignot, T.M., Tost, J., Busato, F., Gut, I., Rebourcet, R., Laissue, P., Tsatsaris, V., Goffinet, F., Rigourd, V., Carbonne, B., Ferre, F. and Vaiman, D. 2007 Expressional and epigenetic alterations of placental serine protease inhibitors: SERPINA3 is a potential marker of preeclampsia. Hypertension 49, 76-83.

Cnattingius, S., Reilly, M., Pawitan, Y. and Lichtenstein, P. 2004 Maternal and fetal genetic factors account for most of familial aggregation of preeclampsia: a population-based Swedish cohort study. Am J Med Genet A 130, 365-71.

Cohen, M., Meisser, A., Haenggeli, L. and Bischof, P. 2006 Involvement of MAPK pathway in TNF-alpha-induced MMP-9 expression in human trophoblastic cells. Mol Hum Reprod 12, 225-32. 
Coolman, M., de Maat, M., Van Heerde, W.L., Felida, L., Schoormans, S., Steegers, E.A., Bertina, R.M. and de Groot, C.J. 2006 Matrix Metalloproteinase-9 Gene -1562C/T Polymorphism Mitigates Preeclampsia. Placenta.

Cowden Dahl, K.D., Fryer, B.H., Mack, F.A., Compernolle, V., Maltepe, E., Adelman, D.M., Carmeliet, P. and Simon, M.C. 2005 Hypoxia-inducible factors 1alpha and 2alpha regulate trophoblast differentiation. Mol Cell Biol 25, 10479-91.

Cross, J.C., Werb, Z. and Fisher, S.J. 1994 Implantation and the placenta: key pieces of the development puzzle. Science 266, 1508-18.

Damsky, C.H. and Fisher, S.J. 1998 Trophoblast pseudo-vasculogenesis: faking it with endothelial adhesion receptors. Curr Opin Cell Biol 10, 660-6.

de Jager, C.A., Linton, E.A., Spyropoulou, I., Sargent, I.L. and Redman, C.W. 2003 Matrix metalloprotease-9, placental syncytiotrophoblast and the endothelial dysfunction of pre-eclampsia. Placenta 24, 84-91.

Duckitt, K. and Harrington, D. 2005 Risk factors for pre-eclampsia at antenatal booking: systematic review of controlled studies. Bmj 330, 565.

Einarsson, J.I., Sangi-Haghpeykar, H. and Gardner, M.O. 2003 Sperm exposure and development of preeclampsia. Am J Obstet Gynecol 188, 1241-3.

Elsheikh, A., Creatsas, G., Mastorakos, G., Milingos, S., Loutradis, D. and Michalas, S. 2001 The renin-aldosterone system during normal and hypertensive pregnancy. Arch Gynecol Obstet 264, 182-5.

Ergaz, Z., Avgil, M. and Ornoy, A. 2005 Intrauterine growth restriction-etiology and consequences: what do we know about the human situation and experimental animal models? Reprod Toxicol 20, 301-22.

Esplin, M.S., Fausett, M.B., Fraser, A., Kerber, R., Mineau, G., Carrillo, J. and Varner, M.W. 2001 Paternal and maternal components of the predisposition to preeclampsia. N Engl J Med 344, 867-72.

Estelles, A., Gilabert, J., Grancha, S., Yamamoto, K., Thinnes, T., Espana, F., Aznar, J. and Loskutoff, D.J. 1998 Abnormal expression of type 1 plasminogen activator inhibitor and tissue factor in severe preeclampsia. Thromb Haemost 79, 500-8.

Estelles, A., Gilabert, J., Keeton, M., Eguchi, Y., Aznar, J., Grancha, S., Espna, F., Loskutoff, D.J. and Schleef, R.R. 1994 Altered expression of plasminogen activator inhibitor type 1 in placentas from pregnant women with preeclampsia and/or intrauterine fetal growth retardation. Blood 84, 143-50.

Fisher, S.J. 2004 The placental problem: linking abnormal cytotrophoblast differentiation to the maternal symptoms of preeclampsia. Reprod Biol Endocrinol 2, 53.

Fournier, T., Pavan, L., Tarrade, A., Schoonjans, K., Auwerx, J., Rochette-Egly, C. and Evain-Brion, D. 2002 The role of PPAR-gamma/RXR-alpha heterodimers in the regulation of human trophoblast invasion. Ann N Y Acad Sci 973, 26-30.

Gerretsen, G., Huisjes, H.J. and Elema, J.D. 1981 Morphological changes of the spiral arteries in the placental bed in relation to pre-eclampsia and fetal growth retardation. $\mathrm{Br} \mathrm{J}$ Obstet Gynaecol 88, 876-81.

Grancha S, Estelles A, Gilabert J, Chirivella M, Espana F, Aznar J. 1996 Decreased expression of PAI-2 mRNA and protein in pregnancies complicated with intrauterine fetal growth retardation. Thromb Haemost 76(5):761-7.

Granger, J.P., Alexander, B.T., Llinas, M.T., Bennett, W.A. and Khalil, R.A. 2002 Pathophysiology of preeclampsia: linking placental ischemia/hypoxia with microvascular dysfunction. Microcirculation 9, 147-60.

Gupta, S., Agarwal, A. and Sharma, R.K. 2005 The role of placental oxidative stress and lipid peroxidation in preeclampsia. Obstet Gynecol Surv 60, 807-16. 
Harrison, G.A., Humphrey, K.E., Jones, N., Badenhop, R., Guo, G., Elakis, G., Kaye, J.A., Turner, R.J., Grehan, M., Wilton, A.N., Brennecke, S.P. and Cooper, D.W. 1997 A genomewide linkage study of preeclampsia/eclampsia reveals evidence for a candidate region on 4q. Am J Hum Genet 60, 1158-67.

He, H., Venema, V.J., Gu, X., Venema, R.C., Marrero, M.B. and Caldwell, R.B. 1999 Vascular endothelial growth factor signals endothelial cell production of nitric oxide and prostacyclin through flk-1/KDR activation of c-Src. J Biol Chem 274, 25130-5.

Hiby, S.E., Walker, J.J., O'Shaughnessy K, M., Redman, C.W., Carrington, M., Trowsdale, J. and Moffett, A. 2004 Combinations of maternal KIR and fetal HLA-C genes influence the risk of preeclampsia and reproductive success. J Exp Med 200, 957-65.

Hu, Z.Y., Liu, Y.X., Liu, K., Byrne, S., Ny, T., Feng, Q. and Ockleford, C.D. 1999 Expression of tissue type and urokinase type plasminogen activators as well as plasminogen activator inhibitor type-1 and type-2 in human and rhesus monkey placenta. J Anat 194 ( Pt 2), 183-95.

Hubel, C.A., Roberts, J.M., Taylor, R.N., Musci, T.J., Rogers, G.M. and McLaughlin, M.K. 1989 Lipid peroxidation in pregnancy: new perspectives on preeclampsia. Am J Obstet Gynecol 161, 1025-34.

Hung, T.H. and Burton, G.J. 2006 Hypoxia and reoxygenation: a possible mechanism for placental oxidative stress in preeclampsia. Taiwan J Obstet Gynecol 45, 189-200.

Iglesias-Platas, I., Monk, D., Jebbink, J., Buimer, M., Boer, K., van der Post, J., Hills, F., Apostolidou, S., Ris-Stalpers, C., Stanier, P. and Moore, G.E. 2007 STOX1 is not imprinted and is not likely to be involved in preeclampsia. Nat Genet 39, 279-80.

Islami, D., Mock, P. and Bischof, P. 2001 Effects of human chorionic gonadotropin on trophoblast invasion. Semin Reprod Med 19, 49-53.

Jauniaux, E., Gulbis, B. and Burton, G.J. 2003 Physiological implications of the materno-fetal oxygen gradient in human early pregnancy. Reprod Biomed Online 7, 250-3.

Jeunemaitre, X., Inoue, I., Williams, C., Charru, A., Tichet, J., Powers, M., Sharma, A.M., Gimenez-Roqueplo, A.P., Hata, A., Corvol, P. and Lalouel, J.M. 1997 Haplotypes of angiotensinogen in essential hypertension. Am J Hum Genet 60, 1448-60.

Kalsheker, N., Morley, S. and Morgan, K. 2002 Gene regulation of the serine proteinase inhibitors alpha1-antitrypsin and alpha1-antichymotrypsin. Biochem Soc Trans 30, 938.

Kanayama, N., Takahashi, K., Matsuura, T., Sugimura, M., Kobayashi, T., Moniwa, N., Tomita, M. and Nakayama, K. 2002 Deficiency in p57Kip2 expression induces preeclampsia-like symptoms in mice. Mol Hum Reprod 8, 1129-35.

Kaufmann, P., Black, S. and Huppertz, B. 2003 Endovascular trophoblast invasion: implications for the pathogenesis of intrauterine growth retardation and preeclampsia. Biol Reprod 69, 1-7.

Kersten, S. and Wahli, W. 2000 Peroxisome proliferator activated receptor agonists. Exs 89, $141-51$.

Kingdom, J.C. and Kaufmann, P. 1997 Oxygen and placental villous development: origins of fetal hypoxia. Placenta 18, 613-21; discussion 623-6.

Knox, K.S. and Baker, J.C. 2007 Genome-wide expression profiling of placentas in the p57Kip2 model of pre-eclampsia. Mol Hum Reprod.

Kobashi, G., Hata, A., Shido, K., Kato, E.H., Yamada, H., Fujimoto, S., Kishi, R. and Kondo, K. 1999 Association of a variant of the angiotensinogen gene with pure type of hypertension in pregnancy in the Japanese: implication of a racial difference and significance of an age factor. Am J Med Genet 86, 232-6. 
Kolben, M., Lopens, A., Blaser, J., Ulm, K., Schmitt, M., Schneider, K.T. and Tschesche, H. 1996 Proteases and their inhibitors are indicative in gestational disease. Eur J Obstet Gynecol Reprod Biol 68, 59-65.

Lachmeijer, A.M., Arngrimsson, R., Bastiaans, E.J., Frigge, M.L., Pals, G., Sigurdardottir, S., Stefansson, H., Palsson, B., Nicolae, D., Kong, A., Aarnoudse, J.G., Gulcher, J.R., Dekker, G.A., ten Kate, L.P. and Stefansson, K. 2001 A genome-wide scan for preeclampsia in the Netherlands. Eur J Hum Genet 9, 758-64.

Liang, G., Salem, C.E., Yu, M.C., Nguyen, H.D., Gonzales, F.A., Nguyen, T.T., Nichols, P.W. and Jones, P.A. 1998 DNA methylation differences associated with tumor tissues identified by genome scanning analysis. Genomics 53, 260-8.

Lyall, F. 2005 Priming and remodelling of human placental bed spiral arteries during pregnancy--a review. Placenta 26 Suppl A, S31-6.

Matrisian, L.M. 1990 Metalloproteinases and their inhibitors in matrix remodeling. Trends Genet 6, 121-5.

Maynard, S.E., Min, J.Y., Merchan, J., Lim, K.H., Li, J., Mondal, S., Libermann, T.A., Morgan, J.P., Sellke, F.W., Stillman, I.E., Epstein, F.H., Sukhatme, V.P. and Karumanchi, S.A. 2003 Excess placental soluble fms-like tyrosine kinase 1 (sFlt1) may contribute to endothelial dysfunction, hypertension, and proteinuria in preeclampsia. J Clin Invest 111, 649-58.

Maynard, S.E., Venkatesha, S., Thadhani, R. and Karumanchi, S.A. 2005 Soluble Fms-like tyrosine kinase 1 and endothelial dysfunction in the pathogenesis of preeclampsia. Pediatr Res 57, 1R-7R.

Moffett-King, A. 2002 Natural killer cells and pregnancy. Nat Rev Immunol 2, 656-63.

Mondon, F., Mignot, T.M., Rebourcet, R., Jammes, H., Danan, J.L., Ferre, F. and Vaiman, D. 2005 Profiling of oxygen-modulated gene expression in early human placenta by systematic sequencing of suppressive subtractive hybridization products. Physiol Genomics 22, 99-107.

Morbidelli, L., Chang, C.H., Douglas, J.G., Granger, H.J., Ledda, F. and Ziche, M. 1996 Nitric oxide mediates mitogenic effect of VEGF on coronary venular endothelium. Am J Physiol 270, H411-5.

Morgan, T., Craven, C., Nelson, L., Lalouel, J.M. and Ward, K. 1997 Angiotensinogen T235 expression is elevated in decidual spiral arteries. J Clin Invest 100, 1406-15.

Myers, J., Mires, G., Macleod, M. and Baker, P. 2005 In preeclampsia, the circulating factors capable of altering in vitro endothelial function precede clinical disease. Hypertension $45,258-63$.

Nakajima, T., Jorde, L.B., Ishigami, T., Umemura, S., Emi, M., Lalouel, J.M. and Inoue, I. 2002 Nucleotide diversity and haplotype structure of the human angiotensinogen gene in two populations. Am J Hum Genet 70, 108-23.

Ness, R.B. and Sibai, B.M. 2006 Shared and disparate components of the pathophysiologies of fetal growth restriction and preeclampsia. Am J Obstet Gynecol 195, 40-9.

Ohkuchi, A., Minakami, H., Aoya, T., Haga, T., Kimura, H., Suzuki, M. and Sato, I. 2001 Expansion of the fraction of Th1 cells in women with preeclampsia: inverse correlation between the percentage of Th1 cells and the plasma level of PAI-2. Am J Reprod Immunol 46, 252-9.

Ostendorf, T., Kunter, U., Eitner, F., Loos, A., Regele, H., Kerjaschki, D., Henninger, D.D., Janjic, N. and Floege, J. 1999 VEGF(165) mediates glomerular endothelial repair. J Clin Invest 104, 913-23.

Page, N.M., Kemp, C.F., Butlin, D.J. and Lowry, P.J. 2002 Placental peptides as markers of gestational disease. Reproduction 123, 487-95.

Parham, P. 1996 Pictures of MHC restriction. Nature 384, 109-10. 
Park, S.K., Dadak, A.M., Haase, V.H., Fontana, L., Giaccia, A.J. and Johnson, R.S. 2003 Hypoxia-induced gene expression occurs solely through the action of hypoxiainducible factor 1alpha (HIF-1alpha): role of cytoplasmic trapping of HIF-2alpha. Mol Cell Biol 23, 4959-71.

Patston, P.A. and Gettins, P.G. 1996 Significance of secondary structure predictions on the reactive center loop region of serpins: a model for the folding of serpins into a metastable state. FEBS Lett 383, 87-92.

Redman, C.W. and Sargent, I.L. 2000 Placental debris, oxidative stress and pre-eclampsia. Placenta 21, 597-602.

Redman, C.W. and Sargent, I.L. 2004 Preeclampsia and the systemic inflammatory response. Semin Nephrol 24, 565-70.

Redman, C.W. and Sargent, I.L. 2005 Latest advances in understanding preeclampsia. Science 308, 1592-4.

Roberts, J.M. 1999 Objective evidence of endothelial dysfunction in preeclampsia. Am J Kidney Dis 33, 992-7.

Roberts, J.M. and Gammill, H.S. 2005 Preeclampsia: recent insights. Hypertension 46, 12439.

Roberts, J.M. and Lain, K.Y. 2002 Recent Insights into the pathogenesis of pre-eclampsia. Placenta 23, 359-72.

Robillard, P.Y., Dekker, G.A. and Hulsey, T.C. 2002 Evolutionary adaptations to preeclampsia/eclampsia in humans: low fecundability rate, loss of oestrus, prohibitions of incest and systematic polyandry. Am J Reprod Immunol 47, 104-11.

Sargent, I.L., Borzychowski, A.M. and Redman, C.W. 2006 NK cells and human pregnancy an inflammatory view. Trends Immunol.

Schjetlein R, Abdelnoor M, Haugen G, Husby H, Sandset PM, Wisloff F. 1999 Hemostatic variables as independent predictors for fetal growth retardation in preeclampsia. Acta Obstet Gynecol Scand 78(3):191-7.

Seeds, J.W. and Peng, T. 1998 Impaired growth and risk of fetal death: is the tenth percentile the appropriate standard? Am J Obstet Gynecol 178, 658-69.

Shibata, E., Nanri, H., Ejima, K., Araki, M., Fukuda, J., Yoshimura, K., Toki, N., Ikeda, M. and Kashimura, M. 2003 Enhancement of mitochondrial oxidative stress and upregulation of antioxidant protein peroxiredoxin III/SP-22 in the mitochondria of human pre-eclamptic placentae. Placenta 24, 698-705.

Sibai, B.M., Ewell, M., Levine, R.J., Klebanoff, M.A., Esterlitz, J., Catalano, P.M., Goldenberg, R.L. and Joffe, G. 1997 Risk factors associated with preeclampsia in healthy nulliparous women. The Calcium for Preeclampsia Prevention (CPEP) Study Group. Am J Obstet Gynecol 177, 1003-10.

Silverman, G.A., Bird, P.I., Carrell, R.W., Church, F.C., Coughlin, P.B., Gettins, P.G., Irving, J.A., Lomas, D.A., Luke, C.J., Moyer, R.W., Pemberton, P.A., Remold-O'Donnell, E., Salvesen, G.S., Travis, J. and Whisstock, J.C. 2001 The serpins are an expanding superfamily of structurally similar but functionally diverse proteins. Evolution, mechanism of inhibition, novel functions, and a revised nomenclature. $\mathrm{J}$ Biol Chem 276, 33293-6.

Staun-Ram, E. and Shalev, E. 2005 Human trophoblast function during the implantation process. Reprod Biol Endocrinol 3, 56.

Tarrade, A., Schoonjans, K., Guibourdenche, J., Bidart, J.M., Vidaud, M., Auwerx, J., Rochette-Egly, C. and Evain-Brion, D. 2001 PPAR gamma/RXR alpha heterodimers are involved in human $\mathrm{CG}$ beta synthesis and human trophoblast differentiation. Endocrinology 142, 4504-14. 
Thompson, R.C. and Ohlsson, K. 1986 Isolation, properties, and complete amino acid sequence of human secretory leukocyte protease inhibitor, a potent inhibitor of leukocyte elastase. Proc Natl Acad Sci U S A 83, 6692-6.

Vaiman, D., Mondon, F., Garces-Duran, A., Mignot, T.M., Robert, B., Rebourcet, R., Jammes, H., Chelbi, S.T., Quetin, F., Marceau, G., Sapin, V., Piumi, F., Danan, J.L., Rigourd, V., Carbonne, B. and Ferre, F. 2005 Hypoxia-activated genes from early placenta are elevated in preeclampsia, but not in Intra-Uterine Growth Retardation. BMC Genomics 6, 111.

van Dijk, M., Mulders, J., Poutsma, A., Konst, A.A., Lachmeijer, A.M., Dekker, G.A., Blankenstein, M.A. and Oudejans, C.B. 2005 Maternal segregation of the Dutch preeclampsia locus at 10q22 with a new member of the winged helix gene family. Nat Genet 37, 514-9.

Venkatesha, S., Toporsian, M., Lam, C., Hanai, J., Mammoto, T., Kim, Y.M., Bdolah, Y., Lim, K.H., Yuan, H.T., Libermann, T.A., Stillman, I.E., Roberts, D., D'Amore, P.A., Epstein, F.H., Sellke, F.W., Romero, R., Sukhatme, V.P., Letarte, M. and Karumanchi, S.A. 2006 Soluble endoglin contributes to the pathogenesis of preeclampsia. Nat Med 12, 642-9.

Verwoerd, G.R., Hall, D.R., Grove, D., Maritz, J.S. and Odendaal, H.J. 2002 Primipaternity and duration of exposure to sperm antigens as risk factors for pre-eclampsia. Int $\mathbf{J}$ Gynaecol Obstet 78, 121-6.

Vogelmeier, C., Hubbard, R.C., Fells, G.A., Schnebli, H.P., Thompson, R.C., Fritz, H. and Crystal, R.G. 1991 Anti-neutrophil elastase defense of the normal human respiratory epithelial surface provided by the secretory leukoprotease inhibitor. J Clin Invest 87, 482-8.

Wang, J.X., Knottnerus, A.M., Schuit, G., Norman, R.J., Chan, A. and Dekker, G.A. 2002 Surgically obtained sperm, and risk of gestational hypertension and pre-eclampsia. Lancet 359, 673-4.

Wang, Y. and Walsh, S.W. 1998 Placental mitochondria as a source of oxidative stress in preeclampsia. Placenta 19, 581-6.

Weber, M., Davies, J.J., Wittig, D., Oakeley, E.J., Haase, M., Lam, W.L. and Schubeler, D. 2005 Chromosome-wide and promoter-specific analyses identify sites of differential DNA methylation in normal and transformed human cells. Nat Genet 37, 853-62.

Witlin, A.G. and Sibai, B.M. 1998 Hypertension. Clin Obstet Gynecol 41, 533-44.

Yoon, J.C., Chickering, T.W., Rosen, E.D., Dussault, B., Qin, Y., Soukas, A., Friedman, J.M., Holmes, W.E. and Spiegelman, B.M. 2000 Peroxisome proliferator-activated receptor gamma target gene encoding a novel angiopoietin-related protein associated with adipose differentiation. Mol Cell Biol 20, 5343-9.

Zhou, Y., Fisher, S.J., Janatpour, M., Genbacev, O., Dejana, E., Wheelock, M. and Damsky, C.H. 1997 Human cytotrophoblasts adopt a vascular phenotype as they differentiate. A strategy for successful endovascular invasion? J Clin Invest 99, 2139-51.

Zhou, Y., Genbacev, O., Damsky, C.H. and Fisher, S.J. 1998 Oxygen regulates human cytotrophoblast differentiation and invasion: implications for endovascular invasion in normal pregnancy and in pre-eclampsia. J Reprod Immunol 39, 197-213. 


\section{Figure legends}

Figure 1: At the foeto-maternal interface of human placenta, villous trees emanate from cotyledons. These trees are composed of two distinct types of villi: floating and anchor villi.

- Floating villi are bathed in maternal fluids which circulate in the intervillous space; these fluids are highly enriched in red cells from the end of the first trimester. They are formed by a mesenchymal axis containing foetal vessels and macrophages (mainly Hofbauer cells). They are surrounded by an internal layer of mononuclear cells called villous cytotrophoblasts (VCT). These cells differentiate and fuse to form a external multinucleated cell layer that constitute the syncytiotrophoblats (ST), which plays a major function as an endocrine and immunological organ as well as a crucial role as a nutrient/oxygen exchange surface.

- Anchored villi are attached to the uterine wall and are characterized by the presence of columns of proliferative cytotrophoblasts that form bridges between the overlying extraembryonic (villous) mesenchyme and the maternal decidual stroma. From the periphery of these columns, large numbers of cytotrophoblast cells detach, become invasive cytotrophoblasts (EVCT) and migrate through the decidua. Eventually they differentiate in intravascular cytotrophoblasts that colonize and transform maternal uterine spiralled arteries.

Figure 2: A model of putative pathways leading to preeclampsia. In a certain way, the disease affects two compartments, maternal and foeto-placental. The causes of the placental defects are presumably to be found in rapid and abnormal cycles of hypoxia and hyperoxia, which may locally cause ischemic lesions (this constitutes a first stage of the disease which does not induce maternal symptoms). The possible origins of these abnormal variations in oxygen pressure may be found in the complex assembly of maternal and paternal predisposing alleles. 
Epigenetic alterations, leading to disruption of gene expression may originate from early gamete manipulation or be settled by abnormal oxygen conditions. The maternal defect (second stage of the disease) is an original association of symptoms that appear separately in other diseases. There is a known impact of the genetic maternal background in terms of genetic association, although causal mutations are not yet known. The current hypothesis for spreading the disease from the placenta to the mother lies in the release of vasoconstrictive and inflammatory peptides and proteins by the placenta as well as trophoblast debris, able to stimulate an abnormal endothelial response in the mother. 


\section{Figure 1}

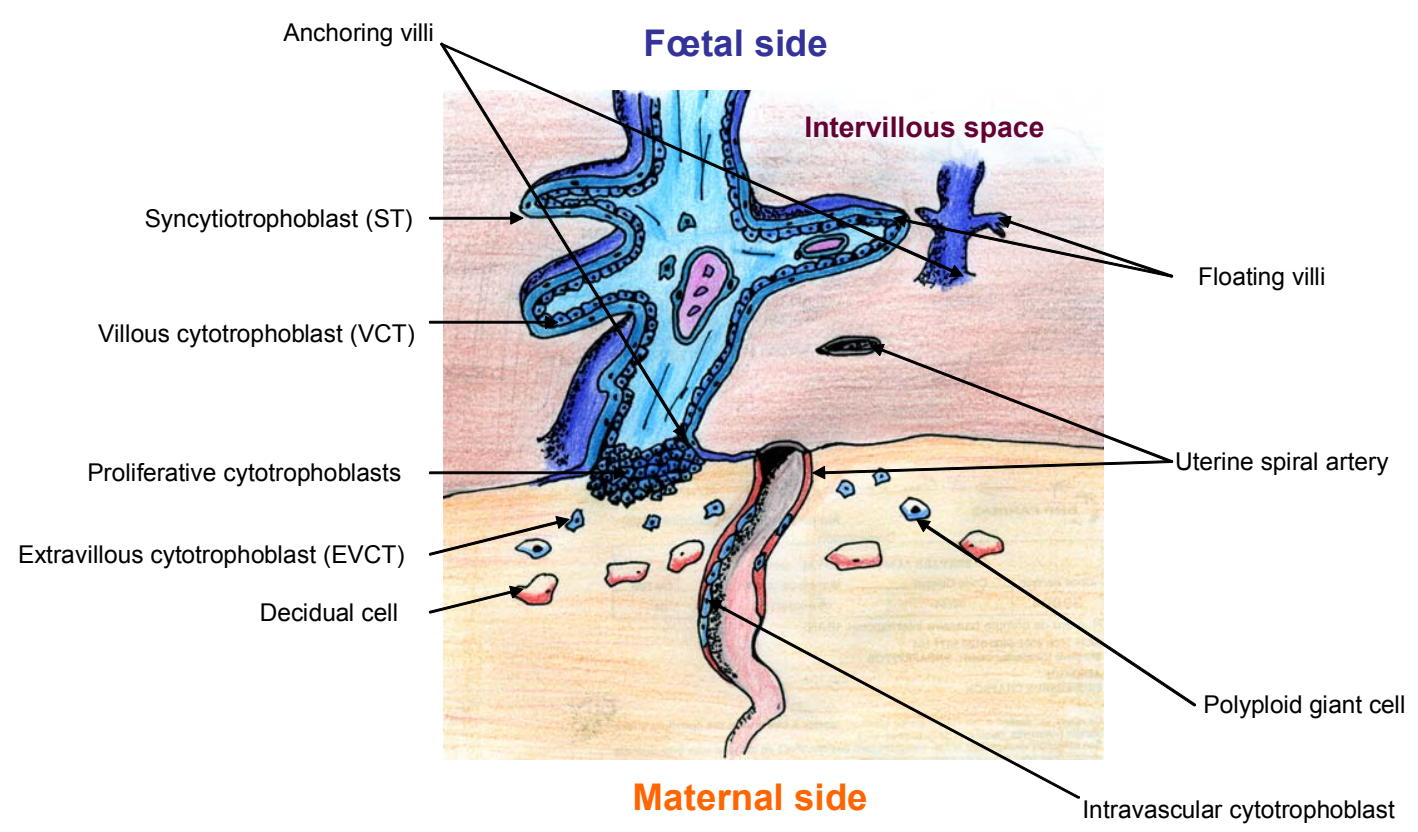


Foeto-placental unit

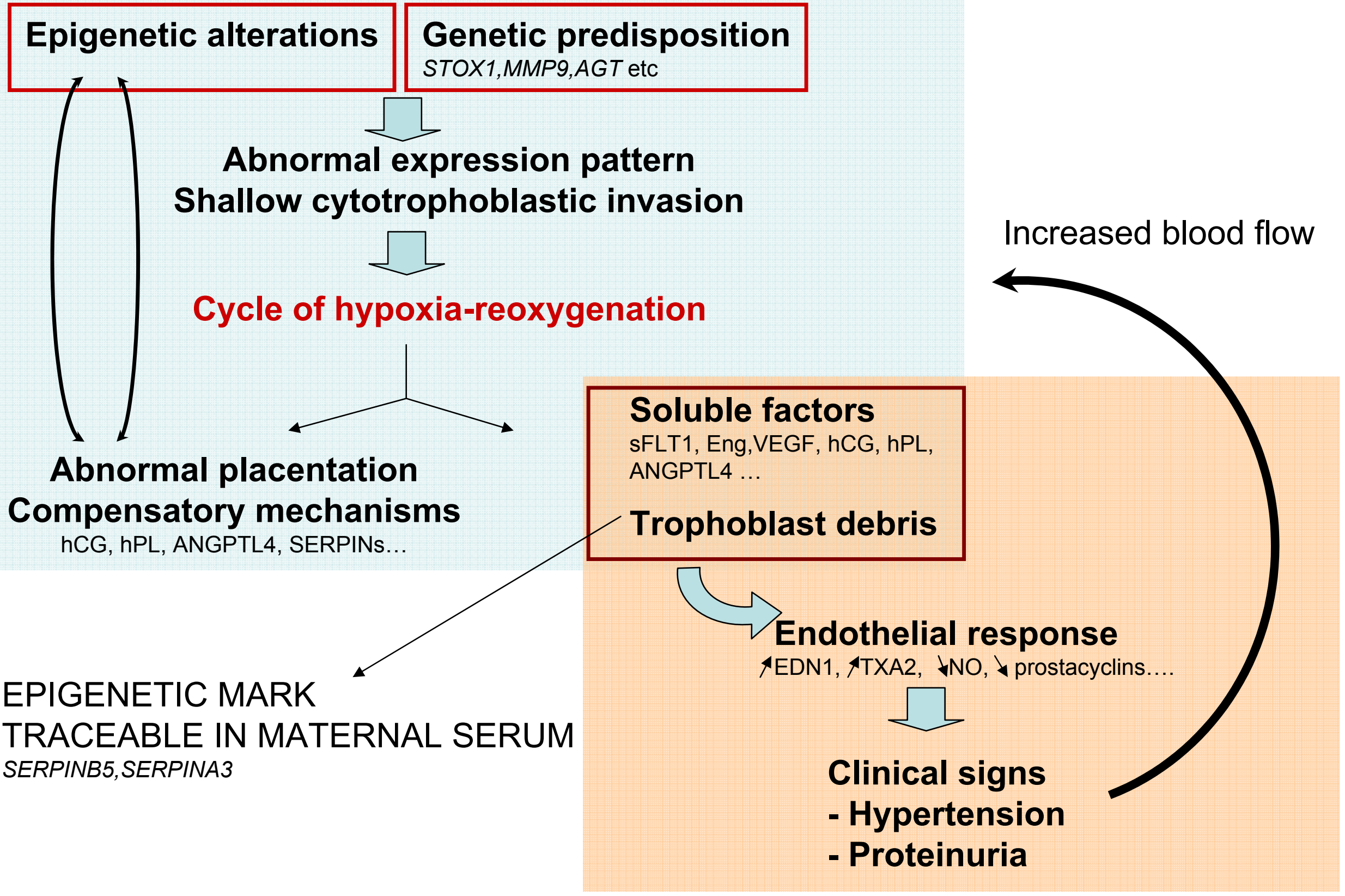

Maternal organism 